\title{
Detección del gen ermB asociado a la resistencia a macrólidos en cepas de Campylobacter aisladas de pollos comercializados en Lima, Perú
}

\author{
Diego Anampa, ${ }^{1}$ Christian Benites, ${ }^{1}$ César Lázaro, ${ }^{1}$ Juan Espinoza, ${ }^{1}$ Pedro Angulo, ${ }^{1}$ Diego Díaz, ${ }^{1}$ \\ Alberto Manchego y Miguel Rojas ${ }^{1}$
}

Forma de citar Anampa D, Benites C, Lázaro C, Espinoza J, Angulo P, Díaz D, et al. Detección del gen ermB asociado a la resistencia a macrólidos en cepas de Campylobacter aisladas de pollos comercializados en Lima, Perú. Rev Panam Salud Publica. 2020;44:e60. https://doi.org/10.26633/RPSP.2020.60

RESUMEN

Objetivo. Detectar la presencia del gen ermB asociado a la resistencia a macrólidos en cepas de Campylobacter spp. aisladas de pollos comercializados en Lima, Perú.

Métodos. Se analizaron 120 muestras de piel de pollo provenientes de tres mercados de los distritos de San Martín de Porres $(n=30)$, Santa Anita $(n=20)$ e Independencia $(n=70)$, ubicados en la Provincia de Lima, Perú. Se realizó el análisis microbiológico de las muestras según las recomendaciones de la norma ISO 10272-1:2017. Para la confirmación por reacción en cadena de la polimerasa (PCR, por sus siglas en inglés) de género y especie, se utilizaron los cebadores (primers) 16-rARN y GlyA e hipO, respectivamente. Para evaluar la sensibilidad antibiótica, se utilizó el agar Müller-Hinton sangre al 5\% con sensidiscos de azitromicina $(15 \mu \mathrm{g})$ y eritromicina $(15 \mu \mathrm{g})$. La detección del gen ermB en cepas con fenotipos resistentes se realizó mediante PCR convencional.

Resultados. Se obtuvo un total de 117 muestras positivas (97,5\%), de las cuales 100\% fueron compatibles con Campylobacter coli (prueba de hipurato negativa) y confirmadas por PCR. La evaluación de resistencia antibiótica en placa para azitromicina y eritromicina dio como resultado $100 \%$ de cepas con fenotipo de resistencia a estos macrólidos, mientras que la PCR para la detección del gen ermB indicó un total de 62 positivas (53\%), que fueron confirmadas por secuenciamiento.

Conclusiones. Estos resultados demuestran que las carcasas de pollo comercializadas en mercados de Lima presentan contaminación por C. coli con una alta resistencia a macrólidos, lo cual puede ser atribuido a la presencia del gen ermB.

Palabras clave Campylobacter, macrólidos; pollos; resistencia microbiana a antibióticos; Perú.

Campylobacter spp. es reconocida a nivel mundial como la principal causa de enfermedades gastrointestinales bacterianas transmitidas por alimentos al ser humano; este hecho se asocia principalmente al consumo de productos avícolas contaminados (1). Estas bacterias han sido aisladas del tracto gastrointestinal de diversos animales, incluidos pollos para carne, donde desarrollan un comportamiento similar al de bacterias comensales, por lo que la presentación de sintomatología es infrecuente (2). Su detección frecuente en carcasas de pollos se relaciona directamente con deficiencias en el proceso de sacrificio y la gran capacidad de este patógeno para desarrollar mecanismos de supervivencia $(1,3)$. En el Perú, la

\footnotetext{
1 Facultad de Medicina Veterinaria, Universidad Nacional Mayor de San

Marcos, Lima, Perú. $\bowtie$ César Lázaro, clazarod@unmsm.edu.pe
} 
carne de pollo es la proteína más consumida, y considerada un producto de primera necesidad; la presentación comercial de "pollo fresco" es la más preferida. Estos productos se venden en mercados tradicionales, donde se sacrifican las aves de forma artesanal y sin garantías sanitarias, lo que favorece la contaminación de la carne (4).

El uso de los antibióticos significó un gran logro para la industria avícola, dado que permitió prevenir y controlar enfermedades, con un beneficio indirecto en la eficiencia alimenticia (5). Los macrólidos, cuyo mecanismo de acción es inhibir la síntesis de proteínas a nivel de la porción $50 \mathrm{~S}$ ribosomal son muy utilizados en China, Estados Unidos y Europa (6). Sin embargo, la exposición frecuente de los pollos para carne a los antibióticos hace que bacterias comensales y patógenas puedan desarrollar diversos mecanismos de resistencia (7). El gen ermB (erythromycin ribosome methylase) brinda resistencia antimicrobiana por medio de la codificación de la metilasa ribosomal para la subunidad 23S, el mecanismo genético emergente más importante para la resistencia a macrólidos (8). El gen ermB está presente en bacterias del género Campylobacter, las cuales son capaces de trasferir e incorporar porciones genómicas a otras bacterias $(9,10)$. Esta característica es relevante en salud pública y un problema emergente, ya que Campylobacter es parte de la microbiota de los pollos para carne (2). Este gen fue reportado por primera vez en el año 2014 en una cepa de C. coli proveniente de un cerdo en China; luego fue detectado en cepas de Campylobacter aisladas de pollos y cerdos en España y Francia, respectivamente (11). La presencia del gen ermB en cepas de C. coli tendría su origen en bacterias grampositivas e incorporado a su genoma por transformación natural, lo que constituye un tipo de transmisión horizontal de genes $(3,12)$.

Asimismo, por medio de estudios in vitro se demostró que C. coli es capaz de transferir con gran facilidad este gen a C. jejuni (11). Esta capacidad es de interés para la salud pública, debido a que C. jejuni es el responsable de más de $90 \%$ de casos de infecciones por Campylobacter en los que la azitromicina, antibiótico del grupo de los macrólidos, es la primera línea de tratamiento (2). Por otro lado, la presencia de este gen también presenta una asociación cada vez más frecuente con islas genómicas multidrogorresistentes, capaces de ser transferidas a diferentes bacterias con suma facilidad $(6,12)$. El objetivo del presente estudio es detectar el gen ermB y su relación con la resistencia bacteriana a los macrólidos en las cepas de Campylobacter aisladas de piel de pollo de los principales mercados de Lima, Perú.

\section{MATERIALES Y MÉTODOS}

\section{Aislamiento microbiológico e identificación bioquímica}

Se recolectaron 120 muestras de piel del cuello $(3 \times 5 \mathrm{~cm})$ y pecho $(5 \times 5 \mathrm{~cm})$ de carcasas de pollo en los locales de expendio de mercados de los distritos de Independencia $(n=70)$, San Martín de Porres $(n=30)$ y Santa Anita $(n=20)$ pertenecientes a la provincia de Lima, Perú. Los mercados seleccionados fueron de tipo "tradicional minorista", definidos como locales cerrados, con puestos distribuidos de forma individual y en secciones definidas, con autorización sanitaria y legal para su funcionamiento, donde se comercializan al por menor productos alimenticios y no alimenticios. Asimismo, los distritos fueron seleccionados por ser los de mayor volumen de distribución de pollo para carne en Lima Metropolitana (13). Las muestras fueron transportadas en temperatura de refrigeración $\left(0-4{ }^{\circ} \mathrm{C}\right)$ al laboratorio de Farmacología y Toxicología Veterinaria de la Facultad de Medicina Veterinaria de la Universidad Nacional Mayor de San Marcos (Lima, Perú) donde fueron picadas para formar pools, que fueron procesados en duplicado según las recomendaciones de la norma ISO 10272-1:2017 (14) para muestras frescas. Luego del crecimiento, y para diferenciar las cepas de C. jejuni de las demás cepas del género Campylobacter, se procedió a realizar la prueba de hipurato.

\section{Confirmación molecular de género y especie}

Para la confirmación molecular, se empleó ácido desoxirribonucleico (ADN) obtenido de las cepas aisladas por medio del Kit Wizard® Genomic DNA Purification (Promega) según las indicaciones del fabricante. Se emplearon los cebadores 16-rRNA-F (ATCTAATGGCTTAACCATTAAAC) y 16-rRNA-R (GGACGGTAACTAGTTTAGTATT) de 857 pb descritos por Frasao (1). Para la confirmación de especie, se emplearon los cebadores GlyA-F (CATATTGTAAAACCAAAGCTTATCG) y GlyA-R (AGTCCAGCAATGTGTGCAATG) para C. coli (133 $\mathrm{pb}$ ) y los cebadores hipO-F (GAAGAGGGTTTGGGTGGTG) y hipO-R (AGCTAGCTTCGCATAATAACTTG) para C. jejuni (735 pb) descritos por Linton (15).

Se utilizaron $5 \mu \mathrm{L}$ de ADN de cada muestra con $20 \mu \mathrm{L}$ de mix de PCR: 6,5 $\mu \mathrm{L}$ de agua libre de nucleasas; $12,5 \mu \mathrm{L}$ de mezcla maestra para PCR a 2X (GoTaq ${ }^{\circledR G} 2$ Green Máster Mix, Promega). En el caso del género, se utilizó $0,5 \mu \mathrm{L}$ del cebador 16-rRNA F $(20 \mu \mathrm{M}) ; 0,5 \mu \mathrm{L}$ del cebador 16-rRNA R $(20 \mu \mathrm{M})$. Para la especie, se realizó un PCR múltiple: $0,25 \mu \mathrm{L}$ del cebador GlyA-F (20 $\mu \mathrm{M}) ; 0,25 \mu \mathrm{L}$ del cebador GlyA-R $(20 \mu \mathrm{M}), 0,25$ $\mu l$ del primers hipO-F $(20 \mu \mathrm{M})$ y $0,25 \mu \mathrm{L}$ del cebador hipO-R $(20 \mu \mathrm{M})$. Una vez completada la mezcla, fue llevada al termociclador $\left(\mathrm{T} 100^{\circledR}\right.$, Biorad) bajo el siguiente ciclo térmico: 10 minutos a $95{ }^{\circ} \mathrm{C}$, seguidos de 40 ciclos compuestos por un minuto a $94{ }^{\circ} \mathrm{C}$, un minuto a $59{ }^{\circ} \mathrm{C}$ para género y $56^{\circ} \mathrm{C}$ para especie, dos minutos a $72{ }^{\circ} \mathrm{C}$ y un paso final de extensión de 10 minutos a $72{ }^{\circ} \mathrm{C}$ e incubación a $4{ }^{\circ} \mathrm{C}$. La visualización y análisis de los productos del PCR se realizó por medio de electroforesis para identificar los productos de cada reacción correspondiente.

\section{Resistencia antimicrobiana en placa}

El análisis fenotípico de la resistencia antimicrobiana se realizó con una dilución de cepas aisladas en solución fisiológica estéril a una concentración de 0,5 en la escala de McFarland. La dilución fue sembrada por medio de hisopo estéril en placas de agar Müller Hinton sangre (5\%), donde se colocaron los discos de azitromicina $(15 \mu \mathrm{g})$ y eritromicina $(15 \mu \mathrm{g})$ para luego incubarlas en medio microaerófilo a $42,5^{\circ} \mathrm{C}$ por 48 horas. La medición de halos de inhibición se realizó según las indicaciones presentadas por EUCAST (16).

\section{Identificación, secuenciamiento y análisis filogenético del gen ermB}

Se realizó una PCR para la identificación y amplificación del gen ermB a todas las muestras con fenotipo resistente a macrólidos encontradas durante el estudio. Para esto se usaron los cebadores ermB-F (GGGCATTTAACGACGAAACTGG) 
y ermB-R (CTGTGGTATGGCGGGTAAGT) descritos por Butcher (17), que permiten obtener un producto de $423 \mathrm{pb}$ de la región más conservada de dicho gen. Se utilizaron $5 \mu \mathrm{L}$ de ADN de cada muestra con $20 \mu \mathrm{L}$ de mezcla de PCR: $12,5 \mu$ de mezcla

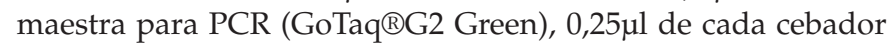
$(20 \mu \mathrm{M})$ y $7 \mu \mathrm{l}$ de agua libre de nucleasas. Una vez completada la mezcla, fue llevada al termociclador (T100 ${ }^{\circledR}$, Biorad) bajo el siguiente ciclo térmico: 10 minutos a $95^{\circ} \mathrm{C}$, seguidos de 40 ciclos compuestos por 40 segundos a $94{ }^{\circ} \mathrm{C}$, un minuto a $55^{\circ} \mathrm{C}$, un minuto a $72{ }^{\circ} \mathrm{C}$ y un paso final de extensión de siete minutos a $72{ }^{\circ} \mathrm{C}$ e incubación a $4{ }^{\circ} \mathrm{C}$. La visualización y análisis de los productos de PCR se realizó de forma similar a lo descrito para género y especie.

Para la validación de esta prueba, se enviaron 10 productos de PCR seleccionados de forma aleatoria que amplificaron el gen ermB. para su secuenciamiento a Macrogen Inc. (Seúl, Corea). Las secuencias obtenidas se ensamblaron y editaron con los programas SeqMan, EditSeq y MegAlign del software Lasergene (DNASTAR, Madison, WI, USA). Nuestras secuencias fueron comparadas con las secuencias de referencia del gen ermB y depositadas en el GenBank (18) con los números de accesos MN461237 al MN461246. El cálculo de distancia genética se realizó con el software del programa MEGA versión 7.0.14 (19) y el dendograma se construyó con el método de máxima verosimilitud basado en el modelo Kimura-2 parámetros. El modelo Kimura-2 parámetros fue seleccionado con la herramienta Find Best DNA/Protein del software MEGA7.

\section{RESULTADOS}

De las 120 muestras, 117 (97,5\%) fueron positivas para Campylobacter spp., distribuidas en 70, 27 y 20 carcasas para los mercados de Independencia, San Martin de Porres y Santa Anita, respectivamente. El análisis molecular confirmó que 100\% de las cepas de Campylobacter spp. obtenidas corresponden a C. coli. La evaluación fenotípica de la resistencia antimicrobiana dio como resultado que $100 \%$ cepas evaluadas fueron resistentes a los macrólidos empleados en el estudio (figura 1). Se obtuvo, en todos los casos, un halo de $8 \mathrm{~mm}$ de diámetro para eritromicina y entre 8 y $16 \mathrm{~mm}$ de diámetro para azitromicina; estas medidas están consideradas por el EUCAST (16) como resistentes. Mediante PCR, se detectó la presencia del gen ermB en $62 / 117(53 \%)$ cepas fenotípicamente resistentes provenientes de los mercados evaluados: 16/30 (59,2\%) en San Martín de Porres, 36/70 (51,4\%) en Independencia y 10/20 (50\%) en Santa Anita (figura 2). Las secuencias nucleotídicas obtenidas del gen ermB se alinearon con secuencias de referencia de este gen presentes en diferentes géneros y especies de bacterias. La distancia filogenética de nuestras secuencias al ser alineadas entre ellas fue de $99,3 \%$ a $100 \%$ de identidad de nucleótidos $\mathrm{y}$, al compararse con las diferentes secuencias de este gen presentes en otras bacterias, dio como resultado una identidad de nucleótidos de $98,5 \%$ a $100 \%$ (figura 3). El resultado del secuenciamiento valida la reacción de PCR para la amplificación del gen ermB y confirma la presencia de este gen en las cepas resistentes a macrólidos aisladas de C. coli en el Perú.

\section{DISCUSIÓN}

La presencia de Campylobacter spp. en 117 de 120 (97,5\%) muestras evaluadas podría indicar una contaminación de la
FIGURA 1. Prueba de sensibilidad antibiótica en placa (agar $\mathrm{MH}$ sangre 5\%, microaerofilia, 48 horas a $42,5^{\circ} \mathrm{C}$ )

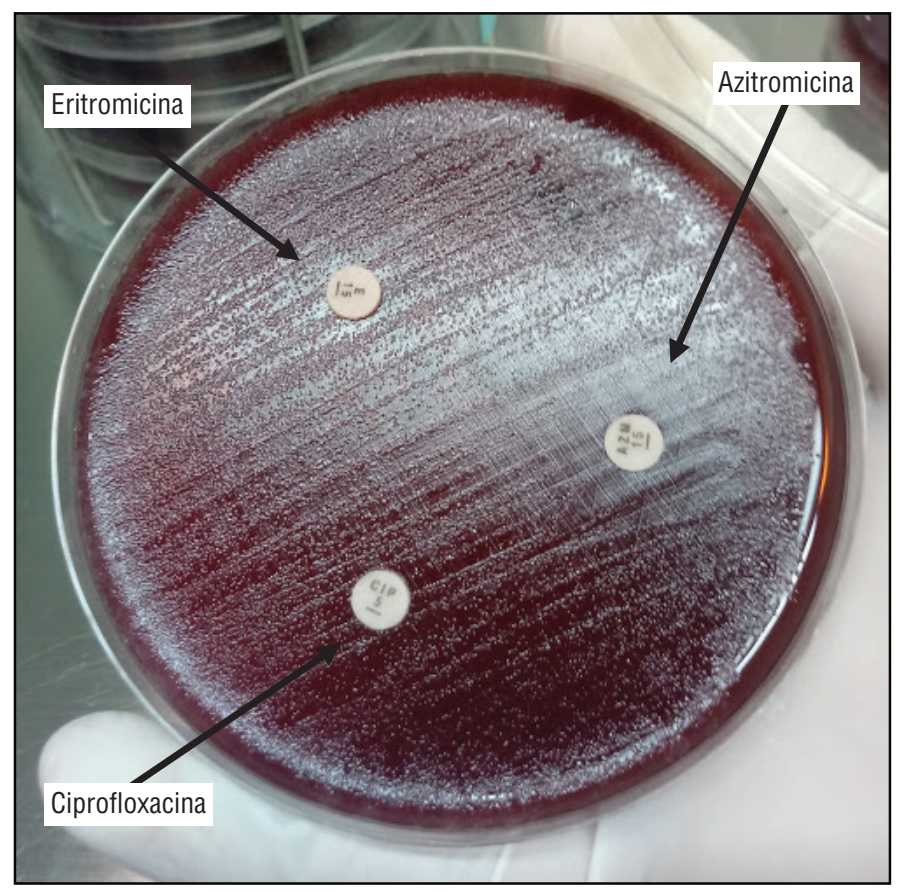

Se observa crecimiento bacteriano en la periferia del disco de eritromicina $(E)$, mientras que el crecimiento es menor en la periferia del disco de azitromicina (AZN); sin embargo, se observan colonias dentro margen delimitado ( $10 \mathrm{~mm})$. E, eritromicina $(15 \mu \mathrm{g})$, AZN , azitromicina $(15 \mu \mathrm{g})$. La interpretación del disco de ciprofloxacina (CIP, $5 \mu \mathrm{g}$ ) también muestra crecimiento bacteriano (las fluoroquinolonas no
se discuten en este estudio).

superficie de la carcasa con contenido fecal del tracto digestivo debido a deficiencias en la práctica en el sacrificio de los pollos, puesto que el origen de este patógeno es el intestino de las aves (1). Es importante señalar que, en los mercados de Lima, es una constante que el sacrificio de los pollos sea realizado en locales cercanos a ellos, que suelen contar con instalaciones inadecuadas y personal poco capacitado. Este tipo de comercialización es aceptada por los consumidores, que asocian estas prácticas con la percepción de adquirir un "pollo fresco" (4).

Nuestros resultados evidencian que 117/117 (100\%) de las cepas aisladas por microbiología fueron confirmadas, mediante pruebas moleculares, como C. coli. Estos hallazgos son contrarios a lo reportado a nivel mundial con respecto a la relación C. jejuni/C. coli, donde el primero representa aproximadamente el 90\% del total de aislamientos en pollos para carne (2). La alta prevalencia encontrada en nuestro estudio es uno de los primeros reportes del comportamiento de Campylobacter spp. en pollos para carne comercializados en Lima Metropolitana. Al no tener datos de la epidemiologia de esta bacteria en el Perú, no sabemos si este escenario es reciente o es de larga data. En el 2012, Lázaro et al. (20) evaluaron 30 carcasas evisceradas colectadas directamente de los locales de beneficio de pollos y encontraron $16,6 \%$ de $C$. coli y $6,6 \%$ de $C$. jejuni.

Lo más probable es que la presencia Campylobacter spp. en la carne de pollo esté relacionada también con una prevalencia alta de esta bacteria en granjas de cría, ya sea por deficiencias en la higiene, bioseguridad y condiciones medioambientales. Con respecto a esto último, la prevalencia es mayor en verano (2), estación en la que fue realizado nuestro muestreo, por lo que los resultados pueden variar si se realiza en época invernal. Otros 
FIGURA 2. Cepas positivas a la PCR de detección del gen ermB con un producto 421 pb

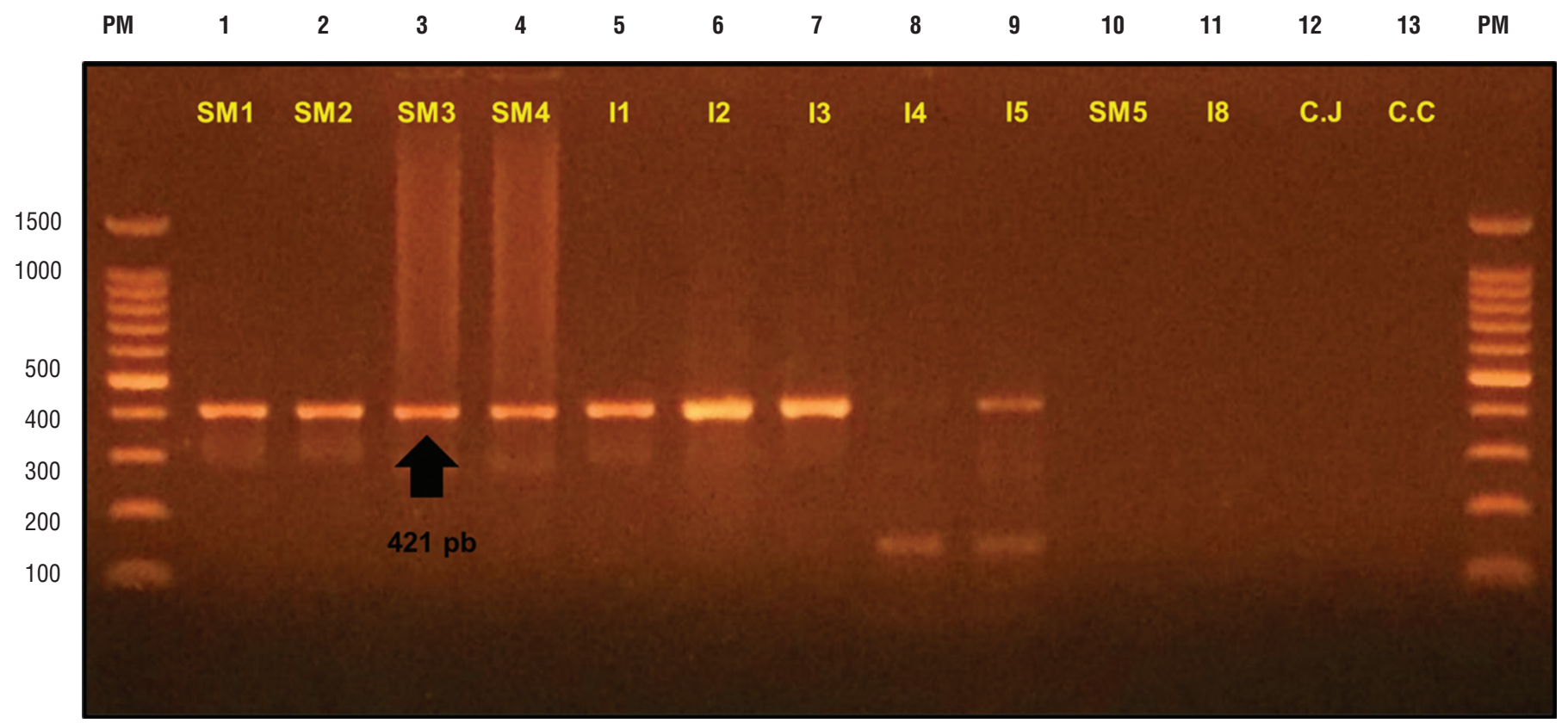

De las líneas 1 hasta la 9, observamos las cepas que contienen el gen ermB; las líneas 10 y 11 son cepas que no contienen el gen ermB; las líneas 12 y 13 son los controles negativos (cepas ATCC de Campylobacter jejuni y C. coli que no tienen el gen plasmidial). PM, marcador de peso molecular de 100 pb (Promegå); SM, muestra recolectada en el distrito de San Martín de Porres; l, muestra recolectada en el distrito de Independencia.

factores que podrían contribuir, aunque en menor medida, son la alta supervivencia de $C$. coli cuando se encuentra en agua (2). Al realizar el muestreo, se pudo observar que las carcasas de pollos se encontraban en depósitos con agua dentro de los locales de expendio, esto podría explicar la elevada presencia de C. coli. Debemos enfatizar también que, en los últimos años, se han realizado modificaciones en los métodos de aislamientos de Campylobacter spp., en la actualidad se utiliza el medio Preston (más específico para C. coli) como preenriquecimiento en lugar del medio Butzler (14).

La evaluación fenotípica de resistencia antimicrobiana para macrólidos dio como resultado $100 \%$ de resistencia para las cepas aisladas. Según Whitehouse et al. (21), C. coli posee una mayor resistencia a macrólidos en comparación con C. jejuni, la cual ha ido en aumento de manera progresiva con el correr de los años. La generación de resistencia antimicrobiana en Campylobacter spp. estaría relacionada con el uso indiscriminado de antibióticos con fines terapeúticos, profilácticos y promotores de crecimiento en la crianza de pollos. Esto es importante para la salud pública, ya que la mayoría de los casos de campilobacteriosis resistentes a antibióticos son atribuidas a cepas de Campylobacter spp. provienentes de alimentos de origen animal (21).

Es bien sabido que $C$. coli posee una gran facilidad para adquirir resistencia antimicrobiana por su variabilidad genética enfocada a la adaptación y supervivencia, que cual le permite sobrevivir a los cambios metabólicos y estructurales de su entorno (3). Dentro de este contexto, debemos señalar que una explicación de la alta prevalencia de C. coli sería la presencia de genes de resistencia, en especial el ermB. Bolinger et al. (22) y Whitehouse et al. (21) describieron que la presencia del gen ermB afectaría la supervivencia de $C$. jejuni y reduciría su colonización en el tracto gastrointestinal del pollo para carne, lo cual no sucedería con C. coli.
La detección del gen ermB en 53\% (62/117) de cepas fenotípicamente resistentes a macrólidos lo posiciona como el principal mecanismo de resistencia en cepas aisladas de mercados de Lima, Perú, con un nivel de detección superior a los hallados en otros países (12). En este estudio, se encontró una alta carga de cepas de $C$. coli resistentes a macrólidos. Esto indicaría, en forma indirecta, la posible circulación y transmisión del gen ermB dentro de los diferentes centros de crianza de pollos para carne (11). Como se mencionó, el gen ermB está asociado a islas genómicas multidrogorresistentes, las cuales poseen genes de resistencia para diferentes grupos de antibióticos (12). Esto constituye un riesgo para la salud pública por la capacidad que posee C. coli para transmitir este y otros componentes de su genoma a C. jejuni, la principal causa de campilobacteriosis en todo el mundo $(2,12)$. Si bien el gen ermB es el principal mecanismo de resistencia a macrólidos, no sería el único. Nuestros resultados muestran que $47 \%$ de cepas de Campylobacter coli deberían su resistencia a macrólidos a genes diferentes del ermB; esto podría dar paso a otros estudios para encontrar la relación de la resistencia fenotípica a otros genes en cepas de Campylobacter spp. (3).

\section{CONCLUSIONES}

La presencia de $C$. coli en casi todas las muestras evaluadas indica una elevada contaminación de las carcasas de pollos en los mercados de Lima, Perú. Esto podría tener relación con deficiencias en el proceso de sacrificio del pollo. La elevada resistencia fenotípica de $C$. coli hallada tanto para eritromicina y azitromicina se atribuye principalmente a la presencia del gen ermB (53\%). Por esto, se sugiere evaluar el uso de macrólidos durante la crianza de pollos para carne. Es necesario implementar programas de vigilancia para Campylobacter spp. en busca de 
FIGURA 3. Dendograma construido a partir de las secuencias parciales del gen ermB de 10 cepas de Campylobacter coli aislados de piel de pollos en mercados de Perú

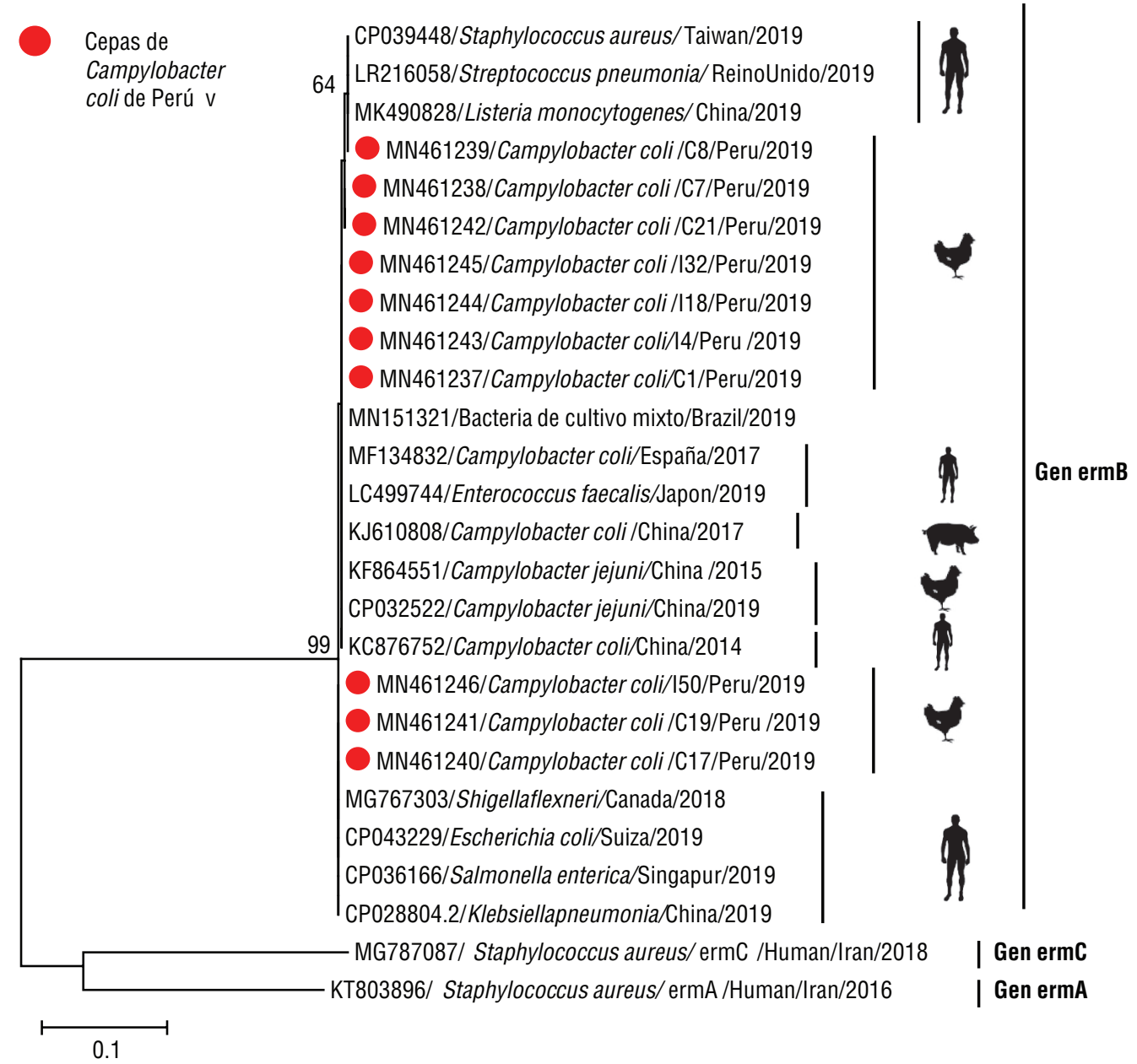

Las secuencias obtenidas fueron alineadas y comparados con secuencias de los genes ermB, ermA y ermC expresados en diferentes géneros y especies de bacterias aisladas de distintas especies animales en diversas partes del mundo. Se observa que la región genética utilizada para la detección de ermB es altamente conservada entre los diferentes gèneros y especies de bacterias que la portan, con una distancia se corrigió mediante el modelo Kimura 2-parámetros. El dendograma fue construido utilizando el método de máxima verosimilitud. El soporte estadístico fue apoyado por un bootstrapping de 1000 repeticiones. Los valores de bootstrap superiores a $75 \%$ se dan en los nodos y las ramificaciones. La escala de distancia está en substituciones/sitio. Los círculos rojos indican las cepas peruanas de Campylobacter coli que expresan el gen ermB. Las 10 secuencias analizadas fueron sometidas al Genbank con los números de acceso MN461237 y MN461246.

controlar su presencia en productos ofrecidos al consumidor, así como el monitoreo de la resistencia antimicrobiana.

Contribuciones de los autores. CL y MR diseñaron y concibieron el experimento. CL, DA, JE, DD y PA colaboraron en el muestreo y la parte microbiológica. MR, AM y CB desarrollaron el analisis molecular y del analisis bioinformático. CL, MR y DA interpretaron los resultados y escribieron el artículo. Todos los autores revisaron y aprobaron la versión final.

Financiamiento. Este trabajo fue financiado por el CONCYTEC- FONDECYT en el marco de la convocatoria "Proyecto
Investigación Básica 2019-01 (número de contrato 405-2019) y por el Vicerectorado de Investigación y Posgrado de la Universidad Nacional Mayor de San Marcos en el marco de la convocatoria "Proyectos de Investigación con financiamiento para Grupos de Investigación 2019".

Conflicto de intereses. Ninguno declarado por los autores.

Declaración. Las opiniones expresadas en este manuscrito son responsabilidad del autor y no reflejan necesariamente los criterios ni la política de la RPSP/PAJPH y / o de la OPS.

\section{REFERENCIAS}

1. Frasao B da S, Marin VA, Conte-Junior CA. Molecular detection, typing, and quantification of Campylobacter spp. in foods of animal origin. Compr Rev Food Sci Food Saf. 2017;16(4):721-34.
2. Sibanda N, McKenna A, Richmond A, Ricke SC, Callaway T, Stratakos AC, et al. A review of the effect of management practices on Campylobacter prevalence in poultry farms. Front Microbiol. 2018;9:2002. 
3. Esson D, Mather AE, Scanlan E, Gupta S, de Vries SPW, Bailey D, et al. Genomic variations leading to alterations in cell morphology of Campylobacter spp. Sci Rep. 2016;6:1-13.

4. Deza-Chiock C, Mendoza-Pérez J. Factores críticos que no permiten el ingreso del pollo beneficiado industrialmente en el canal tradicional en Lima Metropolitana. Lima: Universidad Peruana de Ciencias Aplicadas; 2018. Disponible en: https://repositorioacademico.upc. edu.pe/handle/10757/624852

5. Mehdi Y, Létourneau-Montminy MP, Gaucher ML, Chorfi Y, Suresh $\mathrm{G}$, Rouissi T, et al. Use of antibiotics in broiler production: global impacts and alternatives. Animal Nutrition. 2018;4(2):170-8.

6. Liu D, Liu W, Lv Z, Xia J, Li X, Hao Y, et al. Emerging erm(B)-mediated macrolide resistance associated with novel multidrug resistance genomic islands in Campylobacter. Antimicrob Agents Chemother. 2019;63(7):1-9.

7. Tang Y, Fang L, Xu C, Zhang Q. Antibiotic resistance trends and mechanisms in the foodborne pathogen, Campylobacter. Anim Health Res Rev. 2017;18(2):87-98.

8. Florez-Cuadrado D, Ugarte-Ruiz M, Quesada A, Palomo G, Domínguez L, Porrero MC. Description of an erm(B)-carrying Campylobacter coli isolate in Europe. J Antimicrob Chemother. 2015;71(3):841-3

9. Zhang A, Song L, Liang H, Gu Y, Zhang C, Liu X, et al. Molecular subtyping and erythromycin resistance of Campylobacter in China. J Appl Microbiol. 2016;121(1):287-93.

10. Alfredson DA, Korolik V. Antibiotic resistance and resistance mechanisms in Campylobacter jejuni and Campylobacter coli. FEMS Microbiology Letters. 2007;277(2):123-32.

11. Liu D, Deng F, Gao Y, Yao H, Shen Z, Wu C, et al. Dissemination of erm(B) and its associated multidrug-resistance genomic islands in Campylobacter from 2013 to 2015. Veterinary Microbiology. 2017;204:20-4.

12. Wei B, Kang M. Molecular basis of macrolide resistance in Campylobacter strains isolated from poultry in South Korea. BioMed Res Int. 2018;2018:1-9.

13. Ministerio de Agricultura y Riego de Peú (MINAGRI)). Pollo: comercialización en Lima Metropolitana. Nota Técnica $\mathrm{N}^{\circ} 1$. 2018:11. Disponible en: https://www.minagri.gob.pe/portal/ analisis-economico / analisis-2018?download=12641:pollo-comercializacion-en-lima-metropolitana
14. International Organization for Standardization. ISO 10272-1: Horizontal method for detection and enumeration of Campylobacter spp. Part 1: Detection method. Microbiology of the food chain. 2017. Disponible en: https://www.iso.org/standard/63225.html

15. Linton D, Lawson AJ, Owen RJ, Stanley J. PCR detection, identification to species level, and fingerprinting of campylobacter jejuni and campylobacter coli direct from diarrheic samples. J Clin Microbiol. 1997;35(10):2568-72.

16. The European Committee on Antimicrobial Susceptibility Testing (EUCAST). Breakpoint tables for interpretation of MICs and zone diameters. 2019. Disponible en: http://www.eucast. org / fileadmin/src/media /PDFs /EUCAST_files/Breakpoint_ tables/v_9.0_Breakpoint_Tables.pdf.

17. Sahin O, Shen Z, Zhang Q. Methods to study antimicrobial resistance in Campylobacter jejuni. En: Butcher J, Stintzi A, editors. Campylobacter jejuni: Methods and Protocols. New York, NY: Springer New York; 2017:29-42. Disponible en: https://doi. org/10.1007/978-1-4939-6536-6_4

18. National Center for Biotechnology Information (NCBI). Disponible en: www.ncbi.nlm.nih.gov/nucleotide/

19. Kumar S, Stecher G, Tamura K. MEGA7: Molecular evolutionary genetics analysis version 7.0 for Bigger Datasets. Mol Biol Evol. 2016;33(7):1870-4

20. Lázaro CA, Conte-Junior CA, Vilca MA, Lucas JR, Ramos DD, Manchego A, et al. Molecular identification of Campylobacter jejuni and Campylobacter coli isolated from small-scale poultry slaughterhouse in Lima, Peru. International Journal of Poultry Science. 2012;11(11):677-82.

21. Whitehouse CA, Zhao S, Tate H. Antimicrobial resistance in Campylobacter species: mechanisms and genomic epidemiology. Adv Appl Microbiol. 2018;103:1-47. doi: 10.1016/bs.aambs.2018.01.00

22. Bolinger $\mathrm{H}, \mathrm{Kathariou} \mathrm{S}$. The current state of macrolide resistance in Campylobacter spp.: Trends and impacts of resistance mechanisms. Appl Environ Microbiol. 2017;83(12):1-9.

Manuscrito recibido el 30 de setiembre de 2019. Aceptado para su publicación, tras revisión, el 16 de abril de 2020. 


\section{Detection of the ermB gene associated with macrolide resistance in Campylobacter strains isolated from chickens marketed in Lima, Peru}

ABSTRACT Objective. To detect the presence of the ermB gene associated with macrolide resistance in Campylobacter spp. strains isolated from chickens marketed in Lima, Peru.

Methods. 120 samples of chicken skin from three markets in the districts of San Martin de Porres $(n=30)$, Santa Anita $(n=20)$, and Independencia $(n=70)$, located in the Province of Lima, Peru, were analyzed. Microbiological analysis of the samples was carried out according to ISO standard 10272-1:2017. For the polymerase chain reaction (PCR) confirmation of genus and species, 16-rRNA and GlyA and hipO primers, respectively, were used. For the evaluation of antibiotic sensitivity, the Müller-Hinton agar with $5 \%$ blood, with sensi-discs for azithromycin $(15 \mu \mathrm{g})$ and erythromycin $(15 \mu \mathrm{g})$, was used. For detection of the ermB gene in strains with resistant phenotypes, conventional PCR was used.

Results. A total of 117 positive samples (97.5\%) were obtained; of these, $100 \%$ were compatible with Campylobacter coli (negative hippurate test) and confirmed by PCR. The plate-based assessment of antibiotic resistance to azithromycin and erythromycin resulted in $100 \%$ of strains with a phenotype that is resistant to these macrolides, while the PCR to detect the ermB gene indicated a total of 62 positives (53\%), which were confirmed through sequencing.

Conclusions. These results demonstrate that the chicken carcasses sold in markets in Lima present contamination by $C$. coli with high resistance to macrolides, which can be attributed to the presence of the ermB gene.

Keywords Campylobacter; chickens; drug resistance, macrolides; microbial; Peru.

\section{Detecção do gene ermB associado à resistência a macrolídeos em cepas de Campylobacter isoladas de frangos comercializados em Lima, no Peru}

RESUMO Objetivo. Detectar a presença do gene ermB associado à resistência a macrolídeos em cepas de Campylobacter spp. isoladas de frangos comercializados em Lima, no Peru.

Métodos. Analisamos 120 amostras de pele de frango provenientes de três mercados nos distritos de San Martín de Porres $(n=30)$, Santa Anita $(n=20)$ e Independencia $(n=70)$, situados na Província de Lima, no Peru. Realizamos uma análise microbiológica das amostras de acordo com as recomendações da norma ISO 10272-1:2017. Para a confirmação do gênero e espécie por reação em cadeia da polimerase (PCR), utilizamos os primers 16-rRNA, GlyA e hypO. Para avaliar a sensibilidade antimicrobiana, utilizamos ágar de Müller-Hinton-sangue a 5\% com discos de sensibilidade de azitromicina (15 $\mu \mathrm{g})$ e eritromicina (15 $\mu \mathrm{g})$. A detecção do gene ermB em cepas com fenótipos resistentes foi feita por PCR convencional.

Resultados. Obtivemos um total de 117 amostras positivas (97,5\%), das quais 100\% foram compatíveis com Campylobacter coli (teste do hipurato negativo) e confirmadas por PCR. Na avaliação da resistência antimicrobiana em placa para azitromicina e eritromicina, 100\% das cepas apresentaram fenótipo de resistência a estes macrolídeos, enquanto a PCR para a detecção do gene ermB indicou um total de 62 cepas positivas (53\%), que foram confirmadas por sequenciamento.

Conclusões. Estes resultados demonstram que as carcaças de frango comercializadas nos mercados de Lima apresentam contaminação por C. coli com alta resistência a macrolídeos, o que pode ser atribuído à presença do gene ermB.

Palavras-chave Campylobacter; galinhas; macrolídeos; resistência microbiana a medicamentos; Peru. 